
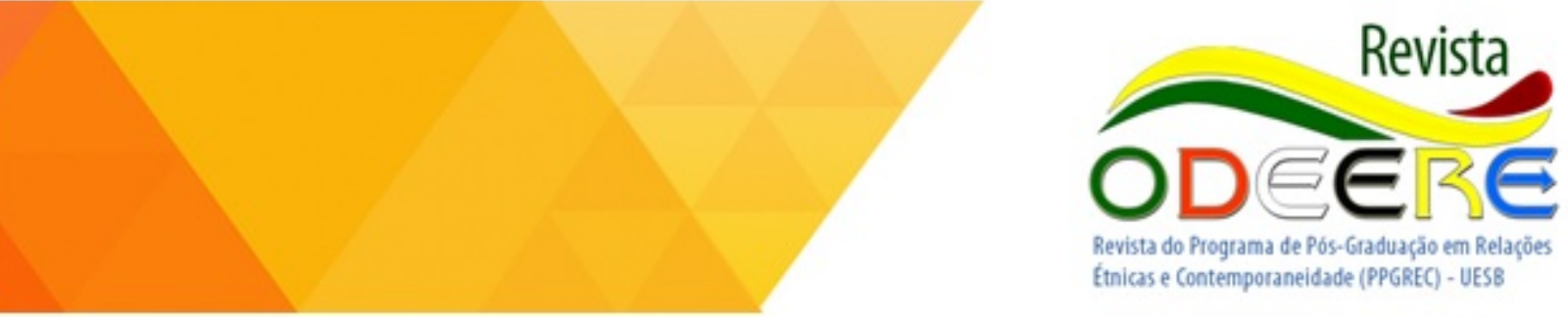

\title{
O MOMENTO DA MÚSICA DA DIÁSPORA AFRICANA
}

\section{THE MOMENT OF AFRICAN DIASPORA MUSIC}

\author{
Dener Santos Silveira \\ Universidade Estadual do Sudoeste da \\ Bahia (UESB) \\ silveiradener@gmail.com
}

José Ricardo Marques dos Santos

Universidade Estadual do Sudoeste da

Bahia (UESB)

domcso@gmail.com

DOI: https://doi.org/10.22481/odeere.v3i6.4297

Resumo: $O$ presente artigo tem como objetivo analisar o conceito de diáspora e as novas linhas de investigação intelectuais abertas a partir do uso crescente do conceito, em especial, na música da Diáspora Africana. Este artigo faz uma reflexão sobre o legado da filosofia moderna no processo de esvaziamento da possibilidade reflexiva da música negra, e também, identifica, no conceito de Diáspora, a condição desestabilizadora de absolutismos nacionais da música no Brasil. Esses absolutismos foram influenciados pela ideia de mestiçagem e promoveram uma centralização na figura do "popular" e do "folclórico" desumanizando as produções subjetivas dos indivíduos e grupos de origem africana. Nesse contexto, informa-se o "momento" de recepção da ideia de Diáspora Africana e como ela legitima o discurso da música negra no Brasil reagindo aos valores e padrões de um sistema de representações que restringem o acesso às culturas diaspóricas e sua reflexividade. Palavras-chave: África, Diáspora, Música Negra, Relações Raciais, pós-colonialismo.

Abstract: The present article has as objective to analyze the concept of diaspora and new lines of research intellectual open from the increasing use of the concept, in particular, on the music of the African Diaspora. This article is a reflection on the legacy of modern philosophy in the process of emptying of the possibility reflective of black music, and also identifies, on the concept of Diaspora, the condition destabilizing of ethnically absolute approaches of national music in Brazil. These ethnically absolute approaches were influenced by the idea of mestizaje and promoted a centralization in the figure of the "popular" and "folkloric" dehumanizing productions ' subjective individuals and groups of african origin. In this context, it informs the "time" of the reception of the idea of the African Diaspora and how it legitimizes the discourse of black music in Brazil, reacting to the values and standards of a system of representations that restrict access to the cultures diaspóricas and its reflexivity.

Keywords: Africa, Diaspora, Black Music, Race Relations, post-colonialism. 


\section{Introdução}

A preocupação com legado do colonialismo na vivência da população negra no Brasil expressa uma nova orientação teórica no horizonte de vários/as pesquisadores/as. Essa orientação é nova por identificar um limite da análise do reconhecimento político das populações negras sob o efeito do nacionalismo particularista. Trata-se do conceito de Diáspora Africana que introduz uma compreensão teórica em relação à necessidade de repensar o impacto da colonização no deslocamento violento da escravidão, na ruína, obsolescência, na destruição de pessoas e grupos de origem africana.

A expressão “Diáspora Africana” surge em 1965, com a menção de George Shepperson e Joseph E. Harris, na Conferência Internacional de História Africana, em Der es Salaam na Tanzânia ${ }^{1}$. O produto resultado da Conferência utiliza a noção de Diáspora Africana pela primeira vez, e contribui para as primeiras iniciativas de repensar as formas de exílio dos africanos na expansão colonial europeia.

A ideia de diáspora, que tinha seu ponto tradicional a partir do entendimento da noção de dispersão, exílio e migração, cuja diáspora judaica era exemplo mais influente sobre o tema na década de 1960, passa, no final do século XX e início do século XXI, a reconhecer a diáspora africana como fenômeno paradigmático pelo desenvolvimento de uma contínua experiência de opressão racial que definiu suas ideologias.

Desde a década de 1960, iniciou-se um crescente uso do conceito de diáspora. Os termos "diáspora" e "diaspórico" apareceram em apenas 12 trabalhos (resumos, teses e dissertações) ao longo de toda a década de 1970, saltando para 10 trabalhos por ano na década de 1980, 60 trabalhos na década de 1990, e mais de 200 por ano até 2008. Os resultados nas bases do Google Acadêmico chegaram a 500 mil e 15 milhões de buscas não acadêmicas pelos termos. ${ }^{2}$ As causas para o crescimento dos usos da diáspora acumulam inúmeras razões que envolvem a massificação e movimentação de pessoas na nova ordem econômica global, e os padrões de guerra que reconfiguram o fluxo migratório e de exílio em várias partes do mundo. ${ }^{3}$

Nesse contexto, é importante que exista uma qualificação do estudo sobre a diáspora, em especial no campo teórico e metodológico, com vistas à auxiliar as novas linhas de investigações intelectuais. As primeiras iniciativas para essa qualificação mostram as classificações que surgem da compreensão da noção de diáspora ao considerar a ruptura com a definição histórica da

\footnotetext{
1 MANNING, Patrick. Africa And The African Diaspora: New Directions Of Study. Journal of African History, 44, 2003, pp. 487-506.

${ }^{2}$ BRUBAKER, Roger. The Diaspora “diáspora”. Ethnic and Racial Studies, Vol. 28 n 1 - January, 2005 pp. 1-19.

${ }^{3}$ BLUTER, Kim. D. Defining Diaspora, Refining a Discourse. Diaspora. 10:2, 2001.
} 
dispersão judaica e reagir ao galut (exílio) tephutzot (dispersão voluntária) a partir do tráfico atlântico de escravos. Enfatizando, desse modo, o status de subalternização como aspecto distintivo no entendimento do termo entre a dispersão judaica e a diáspora africana.

O caráter de disputa entre as concepções são qualificações da ideia de Diáspora. Ser (been), no sentido da dispersão judaica, envolve o retorno à terra prometida e tornar-se (becoming), no sentido de dispersão africana, pressupõe criação, recriação de um sentimento de pertencimento determinado por situações de opressão, rejeição, segregação e discriminação, similares em diferentes contextos (nacionais), com base em características fenotípicas e culturais. ${ }^{4}$

Outra iniciativa refere-se, como continuidade da primeira, à categorização da diáspora africana em relação à "pátria" e a "terra natal". Willian Safran ${ }^{5}$ construiu uma lista de características da diáspora. Essa lista continha as seguintes características: dispersão para dois ou mais locais; mitologia coletiva da pátria; alienação da terra natal; idealização do retorno à pátria e movimento de relação com a pátria.

A sugestão de Butler ${ }^{6}$ para a qualificação e refino da compreensão teórica e metodológica capaz de sustentar novos contornos intelectuais sobre a diáspora, com destaque, para a análise histórica da transição de uma sociedade escravizada para uma sociedade livre, comporta três aspectos: 1) o acesso intersubjetivo com a pátria se dá pela situação de sua subalternização como escravizado 2) A dupla articulação entre a recepção e a segregação no pós-abolição 3) O limite ontológico do negro africano o conduz a ter acesso à consciência apenas na experiência do outro.

A quebra de paradigma sobre a importância da expressão Diáspora Africana nesses referese a uma original contribuição teórica e metodológica, não apenas para os "africanos da diáspora", mas também para o continente africano. Isto é, o campo de Estudos Africanos não encontrou nenhum tipo de reverberação consistente no momento que a análise dos autores ocidentais, remetia a articulação do fenômeno de expropriação colonial europeia como um fenômeno assistido sob a luz da relação escravidão e a liberdade. Processo radicalmente distinto, quando a leitura desse fenômeno foi identificada como "Diáspora Africana". Essa leitura promoveu uma grande contribuição teórica e metodológica sobre África.

No debate contemporâneo da diáspora africana, uma das avaliações para o uso do termo refere-se à interpretação de África distante de um local estanque. Para compreender esse movimento histórico do continente africano, é importante perceber as sensibilidades produzidas

\footnotetext{
${ }^{4}$ SILVÉRIO, Valter R. O Programa Brasil-África na Construção da Ideia de Diáspora Africana. Revista do PPGCS UFRB - Novos Olhares Sociais | Vol.1 - n.1 - 2018.

${ }^{5}$ SAFRAN, William. 1991. "Diasporas in Modern Societies: Myths of Homeland and Return.” Diaspora 1(1): 83-99.

${ }^{6}$ BLUTER, Kim. D. Defining Diaspora, Refining a Discourse. Diaspora. 10:2, 2001
} 
por africanos e africanos da diáspora, bem como, as respostas que fornecem para problemas da modernidade.

Essas sensibilidades se encontram na trajetória semovente imposta pela colonização e podem ser reconhecidas nas tradições afro-atlânticas e seu vocabulário musical. Isto é, estabelecer uma rede particular das ligações feitas entre música, identidades culturais e globalização econômica, e as forças políticas para o projeto mais amplo de análise das sensibilidades musicais diaspóricas no século XX e XXI. ${ }^{7}$

\section{Música da Diáspora Africana}

No Brasil, nas duas últimas décadas, a cena musical negra ganhou importância com uma estética excêntrica. $O$ adjetivo excêntrico não é aleatório. Para Paul Gilroy ${ }^{8}$, a expressão excêntrica classifica os músicos produtores de música afro-brasileira como parte de uma casta distinta de

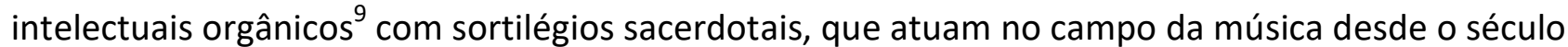
XIX e avançam os anos com força ainda mais intensa.

O músico Chico César, nascido em Catolé do Rocha (1964), interior do Estado da Paraíba no nordeste do Brasil, reconhecido pela estética e autenticidade não traz a música como adorno e um simples estilo. É talvez mais subversivo do que se pensa, diria Stuart Hall ${ }^{10}$, e o próprio Chico César confirmaria:

Quando digo "respeitem meus cabelos, brancos" não falo só de mim nem quero dizer só isso. Debaixo dos cabelos, o homem como metáfora. A raça. A geração. A pessoa e suas ideias. A luta para manter-se de pé e mantê-las, as ideias, flecheiras. É como se alguém dissesse "respeitem minha particularidade". É o que eu digo, como artista brasileiro nordestino descendente de negros e índios. E brancos. Ou ainda no plural: minhas particularidades mutantes. Fala-se em tolerância. Pois não é disso que se trata. Trata-se de respeito. ${ }^{11}$

A necessidade de manifestação flecheira que muitas vezes exacerba o discurso racial tem chamado atenção de muitos/as pesquisadores/as. Há uma engenhosa e interessante forma de comunicação Afroatlântica, em distintos contextos que mostram tradições de diáspora africana e

\footnotetext{
${ }^{7}$ MONSON, Ingrid. The African Diaspora: A Musical Perspective. Routledge New York/London, 2003.

${ }^{8}$ GILROY, Paul. O Atlântico Negro - Modernidade e Dupla Consciência. Rio de Janeiro, Editora 34/UCAM, 2001.

${ }^{9}$ HOOKS,Bell e WEST, Cornel Breaking Bread, Boston: South End Press, 1991.

${ }^{10}$ HALL, S. Da Diáspora. Identidades e Mediações Culturais. (org.) SOVIK, Liv. Belo Horizonte: Editora UFMG, 2009.

${ }^{11}$ Acessado.em.http://www.chicoCésar.com.br/disco_ver.php?titulo=Respeitem\%20meus\%20cabelos,\%20brancos\%202 002
} 
permitem perceber antinomias do princípio nacional. A Banda do Zé Pretinho chegou. ${ }^{12}$ Parece que sim.

Trata-se da produção musical, de negros e negras, com destaque para um tipo de música cuja força expressiva deriva da compatibilização entre melodia e letra. Essa música é construída como uma entonação análoga à fala, potencializada pela ampliação da frequência melódica ${ }^{13}$. A música, de todos os discursos da cultura, foi a que mais incorporou valores culturais da diáspora africana e profundas conexões culturais entre todos os povos de ascendência africana ${ }^{14}$. Segundo Chernoff $^{15}$; Keil ${ }^{16}$, o processo participativo, e as qualidades igualitárias e espirituais da música da diáspora africana, foram idealizados na literatura etnomusicológica. A centralidade da música se desenvolve a partir dos modos de expressão, incluindo a canção, recitação verbal, dança, culto religioso, drama e exibição visual.

A sensibilidade da música contemporânea na diáspora africana ocupa um lugar de raro arcabouço sensitivo, proporcionando um "doce senso de triunfo cultural”" ${ }^{17}$, um empoderamento em suas dimensões culturais, morais, éticas no corpo do africano da diáspora. À medida que as realizações reconhecidas dos/as negros e negras ficam limitadas apenas à música, o empoderamento cultural também serve para o desenvolvimento do esteriotipado sujeito negro essencial, cuja "natureza" define suas potencialidades intuitivas, emocionais e rítmicas.

Essa visão atraente de que a música detém um lugar de definição cultural da diáspora africana traz consigo o papel reinvidicador do uso público da cultura negra, mas pode carregar problemas e complicações. O racismo, a escravidão e o colonialismo foram definidores da ideia de África $^{18}$, e a própria ideia de negritude foi construída a partir da supremacia branca. No entanto, a ideia de música foi construída em oposição à subjugação racial, onde o ethos negro musical unificado foi desenvolvido de forma parcial a partir da experiência contínua do racismo. Forjar uma identidade coletiva por meio de um inimigo comum contribui, por sua vez, para a facilidade com a qual as complexidades da diáspora africana se dissolvem numa relação binária entre preto e

\footnotetext{
${ }^{12}$ Nome da canção que dá nome ao álbum de Jorge Dú́lio Lima Meneses, o Jorge Ben Jor, nascido em 22 de março de 1942, no Rio de Janeiro. Desde pequeno, absorveu as influências culturais africanas que recebeu de sua mãe, Silvia Saint, de descendência etíope. Acessado do portal: http://www.geledes.org.br/patrimonio-cultural/artisticoesportivo/musica/cantores-compositores/13490-hoje-na-historia-1942-nascia-jorge-ben-jor. A Banda do Zé Pretinho é o décimo sexto álbum de estúdio do cantor.

${ }^{13}$ TATIT, Luiz. Elementos para a análise da canção popular, Cadernos de Semiótica aplicada. Vol.1 n², Dezembro/2003.

${ }^{14}$ MONSON, Ingrid. The African Diaspora: A Musical Perspective. Routledge New York/London, 2003.

${ }^{15}$ CHERNOFF, John M. African Rhythm and African Sensibility: Aesthetics and Social Action in African Musical Idioms. Chicago: University of Chicago Press, 1979.

${ }^{16}$ KEIL, Charles. "The Theory of Participatory Descrepancies: A Progress Report.” Ethnomusicology 39(1):1-19. 1995

${ }^{17}$ MONSON, Ingrid. The African Diaspora: A Musical Perspective. Routledge New York/London, 2003.

${ }^{18}$ MONSON, Ingrid. The African Diaspora: A Musical Perspective. Routledge New York/London, 2003.
} 
branco $^{19}$. Como Faye Harrison ${ }^{20}$ observou: Esta construção, de relação binária entre preto e branco, é difícil de arrancar, mesmo no atual contexto de uma crescente sociedade cada vez mais "multicolorida" e "multicultural", na qual a formação racial assume uma multiplicidade de formas, muita dessas formas contestam vigorosamente as construções hegemônicas de brancura e de negritude.

No texto African Diaspora and Colombian Popular Music in the Twentieth Century, Wade ${ }^{21}$ recorre à observação de Brubaker $^{22}$ para defender o caráter imaginário da diáspora africana e da relevância das conexões periféricas estabelecidas. De acordo com Wade ${ }^{23}$ a necessidade da relação entre deslocamento e ponto de origem remete a continuidade na qual a "origem" é entendida como um espaço de imaginação. Ainda que o autor remeta ao uso da diáspora não como conceito analítico, mas como forma adjetiva, como sugeriu Brubaker ${ }^{24}$, para Wade ${ }^{25}$, a ideia de música popular colombiana é caracterizada por uma série de intercâmbios multilaterais, que são dinâmicos e muitas vezes imprevisíveis. Contudo, o autor sinaliza que estas trocas são sempre lidas e interpretadas de maneiras específicas, por diferentes conjuntos de comentaristas interessados em construir certas narrativas, nas quais, muitas vezes, as origens desempenham um papel importante ${ }^{26}$. Desse modo, na concepção de Wade $^{27}$, diáspora pode remeter não ao campo analítico, mas a uma narrativa da origem que fortalece a ideia de semelhança e uniformidade dentro da diversidade e da diferença.

A preocupação de Wade $^{28}$ refere-se à garantia de poder analisar o corpo de conexões periféricas e multilaterais da música na diáspora africana na Colômbia sem se perder no tentador discurso do "absolutismo étnico" ${ }^{29}$. Isto é, essa é uma preocupação na defesa do legado do Black

\footnotetext{
${ }^{19}$ MONSON, Ingrid. The African Diaspora: A Musical Perspective. Routledge New York/London, 2003

${ }^{20}$ HARRISON, Faye V. "Introduction: Expanding the Discourse on 'Race."” American Anthropologist 100(3):609-31. 1998

${ }^{21}$ WADE, Peter. African Diaspora and Colombian Popular Music in the Twentieth Century. Black Music Research Journal Vol. 28, No. 2, University of Illinois 2008.

${ }^{22}$ BRUBAKER, Roger. The Diaspora "diáspora". Ethnic and Racial Studies, Vol. 28 n 1 - January, 2005 pp. 1-19.

${ }^{23}$ WADE, Peter. African Diaspora and Colombian Popular Music in the Twentieth Century. Black Music Research Journal Vol. 28, No. 2, University of Illinois 2008.

${ }^{24}$ BRUBAKER, Roger. The Diaspora "diáspora". Ethnic and Racial Studies, Vol. 28 no 1 - January, 2005 pp. 1-19.

${ }^{25}$ WADE, Peter. African Diaspora and Colombian Popular Music in the Twentieth Century. Black Music Research Journal Vol. 28, No. 2, University of Illinois 2008.

${ }^{26}$ WADE, Peter. African Diaspora and Colombian Popular Music in the Twentieth Century. Black Music Research Journal Vol. 28, No. 2, University of Illinois 2008.

${ }^{27}$ WADE, Peter. African Diaspora and Colombian Popular Music in the Twentieth Century. Black Music Research Journal Vol. 28, No. 2, University of Illinois 2008.

${ }^{28}$ WADE, Peter. African Diaspora and Colombian Popular Music in the Twentieth Century. Black Music Research Journal Vol. 28, No. 2, University of Illinois 2008

${ }^{29}$ Absolutismo Étnico é uma interpretação dos autores ingleses para tratar do reavival do nacionalismo particularista e fundamentalismo de toda sorte. Gilroy propõe que a relação entre o local e universal, para discutir o mundo Atlântico Negro, não se resuma a invocação espúria da perspectiva nacionalista, mas numa unidade nítida e simétrica apreendida na interculturalidade da cultura negra da diáspora.
} 
Atlantic de Paul Gilroy, em especial, na consolidação da ideia de diáspora como vocabulário de interpretação das formas Afro-atlânticas e sua justificação dentro da Teoria Social.

O legado de Paul Gilroy ${ }^{30}$ é construído pela aproximação dos debates dos Estudos Culturais, diáspora africana e da centralidade da música produzida nessa diáspora e sua afirmação contemporânea para identidades transnacionais. O autor inglês, na construção desse legado, visa extrapolar a tradição conceitual da diáspora judaica de relação entre o exílio e o nacionalismo, identificando no terror racial no qual foram expostos os/as negros/as na colonização - enquanto horizonte da ideia de modernidade - uma sustentação para a ideia de diáspora africana e, visa também, concretizar a concepção narrativa emergente sobre a Diáspora em seu livro The Black Atlantic: Modernity and Double-Consciousness.

O impacto dessa construção e seu legado foram relevantes para a orientação da produção cultural dos africanos da diáspora, uma vez que Gilroy não apenas visou a relação entre as narrativas de exílio na metáfora da viagem - o simbolismo do Navio evocando a "Middle passage" e a "homeland imagem visual para a interação transatlântica - na análise de intercâmbio entre a África e o Novo Mundo - binária relação entre os exilados e a "pátria" - mas abordou a multiplicidade de fluxos culturais entre o Caribe, a Grã-Bretanha, o continente africano e América do Norte, sendo o vocabulário musical processo capaz de êxito nessa abordagem.

A música da diáspora africana é um elemento particular importante para a cultura, especialmente nas últimas décadas do século XX. Particular, pois difere, por um lado, entre as demais artes, por sua aceitação ser condicionada pelo aspecto público, coletivo, criando uma comunidade de indivíduos e conjuntamente a isso, paralelos comparativos no gosto e modos de percepção do mundo, qual sejam perfis de identificação. E por outro lado, por ativar estruturas de sentimento, revelando, nas análises dos paralelos comparativos, uma dupla percepção: individual/subjetiva, construída pelo agente da música, e coletiva pelo efeito produzido na sua recepção.

A música da diáspora se mostra como metodologia cultural de interpretação de sentidos. Sua centralidade extrapola a lógica, reduzida de Arte/Estética distante de Ciência, e se aloca como problema cultural, pois ativa estruturas de sentimentos num contexto anuído necessariamente pela aglutinação social - identidade/identificação -, e centraliza a política cultural, estrategicamente selecionada academicamente, por áreas das ciências humanas voltadas para o conceito de diferença, nas quais ganham força dois opostos espinhosos nas Ciências Sociais: a relação entre política e cultura e a relação entre mercado e cultura.

\footnotetext{
${ }^{30}$ GILROY, Paul. O Atlântico Negro - Modernidade e Dupla Consciência. Rio de Janeiro, Editora 34/UCAM, 2001.
} 
Paul Gilroy ${ }^{31}$ afirma que gerações de intelectuais negros tiveram, como formato de propagação do arcabouço crítico da modernidade, um sistema rizomórfico, que cria uma relação de cumplicidade entre os terrores indizíveis da experiência da escravidão e da razão.

Ainda que as conclusões do livro não configurassem uma novidade, a articulação de dispositivos críticos sobre os excessos analíticos que conduziam a absolutismos étnicos foram de grande originalidade. Para a questão da enunciação, Gilroy ${ }^{32}$ recorre a "Poética da Diversidade" de Edouard Glissant ${ }^{33}$ e à preocupação de Glissant em dar respostas a creolização ${ }^{34}$ no discurso produzido pelos autores negros francófonos. Em Martin Delany ${ }^{35}$, o autor busca a junção dos valores pan-africanistas e iluministas, se apropriando das conclusões do abolicionista sobre a identidade, posterior a sua viagem à África. E recorre à noção de "dupla consciência"”36, de W.E.B Dubois $^{37}$, como estruturante na organização de seu discurso reconstruindo por meio da diáspora, o cenário capaz de promover uma ruptura com aquilo que DuBois considerou como o sentimento de existência a partir da consciência de outra pessoa.

Com a articulação desses dispositivos, Gilroy $^{38}$ desafiou a Filosofia Moderna a partir de duas fundamentações construídas por Georg Wilhelm Friedrich Hegel: a dialética do senhor e do escravo e a separação ciência e estética. Gilroy sugere uma reordenação da hierarquia moderna de Hegel dando um status superior à música africana como representação direta da vontade dos escravizados.

\footnotetext{
${ }^{31}$ GILROY, Paul. O Atlântico Negro - Modernidade e Dupla Consciência. Rio de Janeiro, Editora 34/UCAM, 2001.

${ }^{32}$ GILROY, Paul. O Atlântico Negro - Modernidade e Dupla Consciência. Rio de Janeiro, Editora 34/UCAM, 2001.

${ }^{33}$ Edouard Glissant era um discípulo e compatriota do poeta Aimé Césaire , fundador do Movimento de negritude para promover uma cultura africana livre de todas as influências coloniais. Glissant registrou o despertar de povos colonizados em sua coleção de versos Un Champ d'îles (1953; Uma expansão de ilhas) e em seu épico poema Les Indes (1956; The Indies in bilingual edition).

${ }^{34}$ Ao propor o conceito de crioulidade/crioulização, enunciados pela primeira vez em 1989 no Éloge de la créolité, os autores Édouard Glissant e Patrick Chamoiseau relativizam a questão dos identidades, afastando-se ao mesmo tempo do enraizamento - que nega o outro ao afirmar-se - e da alienação, que acarretaria a perda total da memória coletiva. (BERND, 2004)

${ }^{35} \mathrm{O}$ abolicionista Martin Robison Delany era médico e editor de jornal e tornou-se um dos mais influentes e bem sucedidos ativistas antiescravistas do século XIX nos EUA. A biografia de Delany foi grande inspiração para Paul Gilroy na compreensão da ideia de nacionalismo negro e da noção de solidariedade entre os negros americanos.

${ }^{36}$ No Texto de "The Souls of Black Folk" W.E.B. DuBois foi capaz de ver, a partir do desenvolvimento da Teoria da Dupla Consciência o processo de auto-formação que outros teóricos do self que eram cegos à presença e aos efeitos do véu não foram capazes de ver. Em primeiro lugar, o véu sugere a pele mais escura dos negros, que é uma demarcação física da diferença da brancura. Em segundo lugar, o véu sugere a falta de clareza dos brancos para ver os negros como "verdadeiros" americanos. E, por último, o véu refere-se à falta de clareza dos negros para se verem fora do que a América branca descreve e prescreve para eles. (http://xroads.virginia.edu/ ug03/souls/defpg.html)

${ }^{37}$ Após se graduar em Harvard, onde se tornou o primeiro afro-americano a obter um doutorado, se tornou professor de história, sociologia e economia na Universidade de Atlanta. Du Bois foi um dos fundadores da National Association for the Advancement of Colored People (NAACP) em 1909.( https://www.geledes.org.br/w-e-b-du-bois/) DuBois é um forte influenciador do pensamento político negro importante para o projeto Pan-africanista no século XX. DuBois em seu ensaio "The need for na Encyclopedia of the negro"(1945) mostrava uma preocupação com situação política e econômica de África e dos africanos no Novo Mundo. Esse projeto prenunciava um debate em torno da ideia de Diáspora que anos mais tarde configuraria um projeto paradigmático.

${ }^{38}$ GILROY, Paul. O Atlântico Negro - Modernidade e Dupla Consciência. Rio de Janeiro, Editora 34/UCAM, 2001
} 
O debate que permeia a filosofia da história na construção do que se convencionou afirmar e classificar como ocidente, apoiou-se na construção de uma figura abstrata, lúcida e racional, chamada de sujeito de conhecimento, que por meio da auto-determinação do objeto e na busca por uma realidade concreta, define aquilo que Hegel considerou como um "conceito". Aliado a ele, estava o marcador do desejo interrelacional dos indivíduos pelo reconhecimento recíproco. 0 acesso à consciência seria o limite de operacionalização entre o poder de representação no nível de igual condição dos sujeitos livres nas sociedades racionalmente organizadas. No entanto, o nível de igualdade do acesso ao espírito do projeto total de Hegel era a expressão da raiz dual da marginalização do outro, identificado nas etapas da Filosofia da História do filosofo alemão. "Senhor" é o local expressivo da tomada de condição do espírito enquanto "escravo" a natureza imanente da razão material do mundo.

A metáfora psicanalítica do "Senhor e Escravo" de Hegel fundaria, não apenas a racionalidade, mas a própria noção de modernidade. Contudo, como as gerações de filósofos modernos europeus não foram capazes de reconhecer o legado da metáfora no florescer do humanismo iluminista? Por que razão o obstáculo para o potencial de mundo melhor e emancipado não foi capaz de perceber o legado do vocabulário musical africano na diáspora?

Dentre as constrições da metáfora do senhor e do escravo, estava colada a separação entre a estética e ciência. Hegel foi peremptório em considerar a ausência reflexiva do sentimento o território hostil ao desenvolvimento da razão. A emoção dos centros burgueses alemães trazia pouca ou nenhuma atribuição sincera ao desenvolvimento do espírito. A razão é histórica e cumulativa e possui anistia no embate entre o dialético (negativamente racional) e o especulativo (positivamente racional).

A teoria crítica recorre ao valor dialético hegeliano a partir do movimento marxiano rumo ao materialismo, ainda que essa teoria negue a centralidade da história e da natureza. A ideia de potencial de mundo melhor, decorrente do controle das premissas teóricas pela reflexão da prática, isto é, a tentativa de estabelecer prognósticos otimistas sobre o mundo a partir dos obstáculos teóricos descobertos na prática é incapaz, segundo Gilroy ${ }^{39}$, de reconhecer o potencial emancipatório das experiências negras.

Distante de um discurso afro-centrista de retorno ao continente africano, Gilroy advoga em nome das possíveis recombinações e da circulação de ideias no âmbito da metáfora do Atlântico Negro, cujo sentido político não se prende ao grau de fidelidade com o qual se busca produzir as origens comuns. Para o autor, o que importa são as possibilidades que surgem de produção de

\footnotetext{
${ }^{39}$ GILROY, Paul. O Atlântico Negro - Modernidade e Dupla Consciência. Rio de Janeiro, Editora 34/UCAM, 2001
} 
novas formas de comunicação e de compartilhamento intersubjetivo de experiências e das novas criações $^{40}$.

A circulação de ideias se torna assim maior que as bases da nação e do nacionalismo. As letras e canções produzidas pelos africanos na diáspora são recriações lúcidas de um projeto afroatlântico que desarticula, pela negação ao discurso moderno ocidental, a estrutura rígida cuja expressividade dos africanos poderia ser identificada apenas como produto violento do racismo. $\mathrm{O}$ sistema afro-atlântico da música negra se torna um projeto epistemológico de contracultura da modernidade.

Gilroy propõe o constante deslindar da circulação de ideias possíveis a partir da ideia da Diáspora, para ele:

Diáspora é um conceito útil porque ele especifica a pluralização e o traço não idêntico das identidades negras sem celebrações precipitadas. 0 conceito implica possibilidade de traços comuns, mas são traços comuns que não podem ser dados como garantidos. A identidade tem de ser demonstrada em relação à possibilidade alternativa de diferenciação, visto que a lógica da diáspora impõe o sentido da temporalidade e espacialidade, o qual ressalta o fato de que nós não somos o que nós fomos.

Diáspora, como conceito, representa um momento fundamental para discutir e debater novas etnicidades e discutir os aspectos sobre a raça na contemporaneidade. Podemos citar três modelos surgidos desse processo analítico aberto pelo conceito de Diáspora: o primeiro trata-se do modelo americano onde o negro é discursivamente racializado, o segundo versa sobre o modelo apresentado pelos Estudos Culturais e pela abordagem pós-colonial - Stuart Hall e Paul Gilroy fazem parte dessa vertente - onde o negro é portador de uma cultura híbrida e um terceiro processo responde aos anseios de pesquisadores latino americanos, na vertente dos Estudos Decoloniais, analisando o negro no contexto da América Latina, onde há a substituição do conceito de classe pelo de raça como categoria de explanação num projeto de descolonização do saber. Esses novos modelos epistemológicos abrem um novo olhar sobre as circulações de ideias nos assentamentos que experimentaram a escravidão em todo o mundo.

Paul Gilroy, para explanar o seu sistema comunicativo afro-atlântico de música negra, propõe uma jornada marítima pelo mundo do Atlântico Negro desde a expansão colonial europeia. Segundo o autor, o termo Atlântico Negro remete "metaforicamente às estruturas

\footnotetext{
${ }^{40}$ COSTA, Sérgio. Dois Atlânticos: Teoria Social, anti-racismo e cosmopolitismo. Belo Horizonte, Editora UFMG,
} 2006. 
transnacionais criadas na modernidade que se desenvolveram e deram origem a um sistema de comunicações globais marcado por fluxos e trocas culturais" ${ }^{41}$. A ideia de Gilroy possibilita um rearranjo da mecânica cultural e histórica do pertencimento das colônias negras esparsas pelo atlântico. Propondo a formação de uma rede na qual, as populações negras durante a diáspora africana, construíssem uma cultura que não pudesse ser identificada apenas, enquanto, cultura africana, americana, caribenha, ou britânica, mas de forma simultânea.

Uma das preocupações de Gilroy ${ }^{42}$ está na lógica do pertencimento. Ele questiona a definição de cultura nacional herdada do princípio liberal de autodeterminação à nação, tentando encontrar conexões possíveis entre conceitos de raça e etnia, nação e nacionalidade para, justamente, refazer o caminho analítico no intuito de romper com a fixidez da identidade étnica e da unidade nacional.

A diáspora, segundo Gilroy, rompe a sequência dos laços explicativos entre lugar, posição e consciência, e consequentemente, rompe também com o poder do território para determinar a identidade.

A partir da concepção de diáspora, foi construída uma rede de comunicação transnacional que criou uma nova situação de lealdade e identidade que desconsidera as estruturas e os pressupostos do Estado-nação e redefine as formas de ligação e identificação no tempo e no espaço. O modelo de análise, no seu interior, propõe a desterritorialização da cultura em oposição à ideia de uma cultura territorial fechada e codificada no corpo. "Sob a chave da diáspora nós poderemos então ver não a raça, e sim formas geo-políticas e geo-culturais de vida que são resultantes da interação entre sistemas comunicativos e contextos que elas não só incorporam, mas também modificam e transcendem". ${ }^{43}$

O intercambio de ideias promovidas pela noção de diáspora favorece um tráfico de informações que destrói fronteiras étnicas do Estado-nação. Este mesmo circuito comunicativo dá permissão a populações desconexas territorialmente de interagirem, conversarem e efetuarem trocas culturais. "A ideia de culturas viajantes foi um instrumento valioso para desagregar as suposições complacentes e irrefletidas a respeito de uma história cultural sedentária” ${ }^{44}$.

\footnotetext{
${ }^{41}$ SANTOS, Eufrázia Cristina Menezes. Resenha: Gilroy, Paul. O Atlântico Negro. Modernidade e dupla consciência, São Paulo, Rio de Janeiro - REVISTA DE ANTROPOLOGIA, SÃO PAULO, USP, 2002, V. 45 N 1, p.273.

${ }^{42}$ GILROY, Paul. O Atlântico Negro - Modernidade e Dupla Consciência. Rio de Janeiro, Editora 34/UCAM, 2001

${ }^{43}$ GILROY, Paul. O Atlântico Negro - Modernidade e Dupla Consciência. Rio de Janeiro, Editora 34/UCAM, 2001, p. 25

${ }^{44}$ GILROY, Paul. O Atlântico Negro - Modernidade e Dupla Consciência. Rio de Janeiro, Editora 34/UCAM, 2001, p. 22.
} 
Segundo Santos ${ }^{45}$ o mar indica ideia de contaminação, mistura, movimento, coerente com a perspectiva de análise adotada que situa o mundo do Atlântico Negro em uma rede entrelaçada entre o local e o global.

Já o Navio é um sistema vivo, microcultural e micropolítico em movimento que coloca em circulação, ideias, ativistas, artefatos culturais e políticos, para além de sua função no imaginário funcional de transporte, é dotado de significância simbólica. Ele é histórico e representa o objeto que possibilitou o contato pan-africano e a transferência cultural pelo planeta sendo o agente contaminador.

O entendimento da história política e cultura negra no ocidente nos orienta a uma maior atenção “à complexa mistura entre ideias e sistemas filosóficos e culturais europeus e africanos” ${ }^{46}$

A ausência de estudos sobre a história cultural de africanos é consequência do efeito do nacionalismo. A análise da cultura do Atlântico Negro é, para além de sua riqueza, capaz de dar visibilidade a esta nova face reduzida da história cultural: a relação dos negros com a modernidade ocidental. O corpo negro criou uma reflexão única sobre os problemas da modernidade e suas contradições. Essa reflexão se mantém viva nas lutas de resistência políticas e culturais de seus descendentes.

Frantz Fanon ${ }^{47}$ discorre sobre essa premissa considerando que o legado para raça, no advento moderno, foi construído sob o discurso/linguagem humanista olocou a negrura do continente africano no campo da experiência, naquilo que o autor martiniquenho denominou - a partir de Merleau Ponty - de experiência "vivida" do negro. A habilidade de Fanon foi de identificar a coisificação expressa na "vivência" dos negros, na qual o controle se dá na objetificação coordenada pelo sujeito. Essa preocupação inicia com o questionamento da natureza da "consciência" que, ao se fechar na ideia rígida de sujeito, promoveu a incapacidade de existência do sujeito negro.

Fanon $^{48}$ insere a ideia de uma ontologia do sujeito negro. A razão imanente de negação da consciência dos negros promove a incapacidade de "acesso ao espírito" no sentido hegeliano, bem como, na virada intersubjetiva de Habermas. O negro é experiência, natureza e está localizado na coisificação e no destino circundante do sujeito ocidental. Destarte, é na relação

\footnotetext{
${ }^{45}$ SANTOS, Eufrázia Cristina Menezes. Resenha: Gilroy, Paul. O Atlântico Negro. Modernidade e dupla consciência, São Paulo, Rio de Janeiro - REVISTA DE ANTROPOLOGIA, SÃO PAULO, USP, 2002, V. 45 N 1.

${ }^{46}$ SANTOS, Eufrázia Cristina Menezes. Resenha: Gilroy, Paul. O Atlântico Negro. Modernidade e dupla consciência, São Paulo, Rio de Janeiro - REVISTA DE ANTROPOLOGIA, SÃO PAULO, USP, 2002, V. 45 N 1.p. 275.

${ }^{47}$ FANON, Frantz. Pele negra máscaras brancas (1951). Título original: "Peau noire, masques blancs". Salvador: EDUFBA, 2008.

${ }^{48}$ FANON, Frantz. Pele negra máscaras brancas (1951). Título original: "Peau noire, masques blancs". Salvador: EDUFBA, 2008.
} 
com a prática, da Filosofia prática desenvolvida na moral e ética Kantiana, que Fanon enfatiza o momento de ruptura, isto é, de transformação. Uma descolonização!

Franz Fanon e W.E.B Dubois representam, no processo de compreensão da Diáspora, seus pilares mais sólidos. As interpretações sobre os efeitos do racismo, realizadas de forma conectada em contextos distintos, mostram uma "commom form" de perceber as estrutura de organização da sociedade moderna. Por que não admitir, como sugeriu Paul Gilroy, uma engenhosa comunicação atlântica capaz de mostrar as antinomias da nação e da raça? A música dos africanos da diáspora negra apresenta uma desconexa relação geográfica e uma intensa agenda de regularidades de variáveis estéticas e históricas, nos assentamentos que experimentaram a escravidão e a colonização.

Se verificarmos a trajetória de três personagens, os quais podem ser considerados como "pilares da música nordestina", são eles: João do Vale ${ }^{49}$, Jackson do Pandeiro ${ }^{50}$ e Luiz Gonzaga ${ }^{51}$, chama a atenção como, por um lado a clivagem de classe social, e a condição socioeconômica dos sujeitos sobressaem na análise, e por outro, o espectro quase essencial do "nordeste" como sentido comunitário. As barreiras entre os estados são irrelevantes, a história dos sujeitos se homogeneíza na condição de nordestinos e as reflexões sobre raça são sempre colocadas quando citadas - em segundo plano.

Vejamos o comentário de Ferreira Gullar ${ }^{52}$ sobre João do Vale, Jackson do Pandeiro e Luiz Gonzaga:

"Devo dizer que considero João do Vale uma das figuras mais importantes da música popular brasileira. Se é certo que em 1964-65, quando se realizou pela primeira vez o show Opinião, os grandes centros do país

\footnotetext{
49 João Batista do Vale, o João do Vale, nasceu em Pedreira, no Maranhão, em 11 de outubro de 1934. Os pais eram agricultores pobres, e, como muitos jovens pobres, auxiliava nas despesas da casa, vendendo balas, doces e bolos que a mãe fazia. Em torno dos 13 anos de idade, foi para São Luís do Maranhão. As habilidades de compositor já começaram a aparecer nesse período, pois se integrou a um grupo de Bumba Meu Boi, o "Linda Noite", como "amo". (http://antigo.acordacultura.org.br/herois/heroi/joaovale).

${ }^{50}$ Cantor, instrumentista e compositor, José Gomes Filho, conhecido como Jackson do Pandeiro, nasceu em Alagoa Grande, Paraíba, no dia 31 de agosto de 1919, filho do oleiro José Gomes e da cantora de coco pernambucana Flora Mourão (Glória Maria da Conceição). Aos oito anos, começou a tocar zabumba e passou a acompanhar sua mãe nas festas de Alagoa Grande. Em 1932, após a morte de seu pai, mudou-se com a mãe e os irmãos para a cidade de Campina Grande, também na Paraíba, onde começou a trabalhar como entregador de pão e engraxate, para ajudar a sustentar a família.(Fundação Joaquim Nabuco)

${ }^{51}$ Luiz Gonzaga (1912-1989) foi músico brasileiro. Sanfoneiro, cantor e compositor, recebeu o título de "Rei do Baião". Foi responsável pela valorização dos ritmos nordestinos, levou o baião, o xote e o xaxado, para todo o país. A música "Asa Branca" feita em parceria com Humberto Teixeira, gravada por Luiz Gonzaga no dia 3 de março de 1947, virou hino do nordeste brasileiro. Luiz Gonzaga (1912-1989) nasceu na Fazenda Caiçara, em Exu, sertão de Pernambuco, no dia 13 de dezembro de 1912. Filho de Januário José dos Santos, o mestre Januário, "sanfoneiro de 8 baixos" e Ana Batista de Jesus. O casal teve oito filhos. Luiz Gonzaga desde menino já tocava sanfona.

${ }^{52}$ Ferreira Gullar, pseudônimo de José Ribamar Ferreira foi um poeta, crítico de arte, biógrafo, tradutor, memorialista e ensaísta brasileiro e um dos fundadores do neoconcretismo.
} 
tomaram conhecimento de sua existência e lhe reconheceram os méritos de compositor, não é menos certo que pouca gente se deu conta do que ele realmente significa como expressão de nossa cultura popular. Isso se deve ao fato de que João do Vale não é um compositor de origem urbana e que só agora se começa a vencer o preconceito que tem cercado as manifestações populares sertanejas. É verdade que em determinados momentos, com Luiz Gonzaga e Jackson do Pandeiro, essa música conseguiu ganhar o auditório nacional, mas para, em seguida, perder o lugar conquistado. É que o Brasil é o grande e diversificado. Basta dizer que, quando João do Vale se tornou um nome nacional, já tinha quase trezentas músicas gravadas, que o Nordeste inteiro conhecia e cantava, enquanto no Sul ninguém ainda ouvira falar nele. ${ }^{.53}$

As análises sempre recorrem à construção do universo nordestino, a importância da cultura popular e o legado do que Paul Gilroy denominou de "absolutismo étnico". Essas conclusões não se apresentam como novidade, uma vez que a relação entre cultura nacional e identidade nacional figurou como um problema central, deixando uma relação perspectiva com outros contextos, como por exemplo, o contexto latino-americano. A utilização metodológica de uma grande narrativa cúmplice do discurso de modernidade e de emancipação irrealizável também não é nenhuma novidade, mas opera como norte para a compreensão da realidade social. No Brasil, o contexto não foi diferente.

Ao mostrar a vida de três personagens importantes na música brasileira, reiteramos em perspectiva que eles são músicos negros, descendentes de ex-escravos e partilharam de forma agonizante a experiência da escravidão. A negociação que fizeram em vida em prol de seu reconhecimento não passou daquilo que infelizmente Fanon já havia alertado: "enclausurado nesta objetividade esmagadora, implorei ao outro. Seu olhar libertador, percorrendo meu corpo subitamente livre de asperezas, me devolveu uma leveza que eu pensava perdida e, extraindo-me do mundo, me entregou ao mundo" 54 .

"Preto sujo" ou "Olhe, um preto!" 55 : Essa é a consideração de Frantz Fanon para concluir, de forma dolorosa, a tarefa irrealizável de garantir a existência ontológica do ser negro. 0 paradoxo existencial para os negros no mundo colonial faz com que Fanon correlacione as figuras do colonizador e do colonizado. Os negros aceitam um mundo cuja experiência existencial é negada no mesmo sentido de desejo ao lugar do branco. A metáfora da máscara branca é a alegoria capaz de anistiar o fardo da negrura para a garantia de plenitude de sua existência. Longe

\footnotetext{
${ }^{53}$ Acessado em 05/06/15 - http://www.cecac.org.br/MATERIAS/Joao_do_Vale.htm

${ }^{54}$ FANON, Frantz. Pele negra máscaras brancas (1951). Título original: "Peau noire, masques blancs". Salvador: EDUFBA, 2008, p. 103.

${ }^{55}$ FANON, Frantz. Pele negra máscaras brancas (1951). Título original: "Peau noire, masques blancs". Salvador: EDUFBA, 2008, p. 103.
} 
de buscar um refúgio para naturalizar essa correlação entre brancos e negros, Fanon está justamente, negando a premissa hegeliana de dialética primitiva, promovida pela cooperação do "escravo" com o "senhor" na lógica de reconhecimento, impondo a ontologia de um sujeito negro que desafia a ambição ocidental de fixidez no sujeito do conhecimento. Fanon propõe uma fenomenologia sociogênica para análise do mundo social, pois na construção de acesso à consciência via um sujeito do conhecimento ocidental, há um cancelamento da subjetividade dos negros. Esse cancelamento da subjetividade indica que os negros acessaram o inferno em terra. A patologia do racismo impõe ao negro que a experiência negra não deveria existir, uma vez que negros não têm um ponto de vista.

E não seria muito diferente se ao invés de vermos Jackson do Pandeiro, Luiz Gonzaga e João do Vale classificados como um "preto" víssemos classificados como um "nordestino".

O destino foi cruel com os três personagens. Morreram pobres, sim. Mas esse não é o único problema. Morreram tentando apenas ser aquilo que consideravam ser, mas que foram impedidos de mostrar. A realeza imposta pelas indústrias culturais, Rei do Ritmo (Jackson do Pandeiro), Rei do Baião (Luiz Gonzaga), O poeta do Povo (João do Vale) aos seus personagens, se transformou de forma agonizante: se tornaram objetos em meio a outros objetos. O Pandeiro, a sanfona e o povo (cultura popular) foram iguais ou até mais reconhecidos que seus donos.

As produções musicais dos músicos negros (Jackson do Pandeiro, Luiz Gonzaga e João do Vale) se tornaram manifestações puras do universo do popular e das manifestações folclóricas, como coisas do povo. O imperialismo do popular opera como fenômeno do absolutismo étnico e também desumaniza, negando a subjetividade dos agentes da música que a produziu. $O$ racismo invisibiliza as potencialidades africanas no Brasil, na mesma medida que desumaniza e desautoriza a vida plena das pessoas. A música se tornou o escape existencial cuja dimensão, invisível à razão, solidificou os sentimentos de negros/as nas marcas das canções da música negra.

\section{Comunicação e Movimento - o momento da Música da Diáspora Africana}

A compreensão das estruturas de sentimento fornecidas nas sensibilidades no contexto da produção musical de africanos na diáspora merece um desfecho mais contundente. As apropriações realizadas por meio da marca de Música Popular brasileira/MPB no Brasil consistiram na reprodução dos valores africanos na sociedade brasileira como elementos subalternizados. Todo marcador de subjetividade africana, na produção cultural negra, foi construído à sombra da ideia de nação. Dito de outra forma, o nacionalismo produzido como resultado do desejo de 
modernização da nação e de resposta às vicissitudes culturais, orientadas sobremaneira pela interrelação racial da ideia de mestiçagem de Gilberto Freyre, orientou o violento destino de africanos e também de indígenas no Brasil.

É exatamente nesse contexto que a ambição de uma estratégia desterritorializada pode representar um novo olhar para a compreensão da história afro atlântica. A noção de diáspora africana é uma forma de desarticulação dos valores nacionais que se organizam como valores étnicos. Toda e qualquer cultura diaspórica passa a ser caracterizada como híbrida (sincretismo e criolização) e, desse modo, é obrigada a produzir um sistema de representações com normas e valores distantes das sensibilidades da própria cultura.

A ruptura com esse nacionalismo é percebida no movimento e na comunicação das estratégias da música da diáspora africana. A ideia de "comunicação" e de "movimento" são expressões classificatórias. A música negra no Brasil se tornou comunicativa, no momento em que as tensões do estilo e do gosto foram homogeneizadas pelos valores nacionalistas. Essa produção de discurso se tornou necessária para gerar um conflito lógico das experiências de racialização.

Mas apenas se comunicar não é suficiente. É necessário que o discurso produzido se movimente. Esse movimento ocorre na negação da forma endógena de produção da pátria.

A canção Refavela, de Gilberto Gil, mostra o caráter essencialmente urbano da produção negra e sua necessidade de movimento. Esta canção inaugurou um novo formato para visão sobre a música produzida por negros. Composta em 1977, num álbum com o mesmo nome, Refavela é, segundo Gilberto Gil, fruto da experiência de participação do Festival de Arte e Cultura Negra/Festac, em Lagos na Nigéria. Nesta experiência, ele conta sobre o re-encontro com a paisagem suburbana dos conjuntos habitacionais semelhantes aos brasileiros. A motivação para o título veio de dois fatores: o primeiro pelo compromisso conceitual em prefixar o título do novo trabalho de motivação urbana, em contraponto ao de Refazenda (álbum antigo) de inspiração rural. O segundo nasceu da experiência da FESTAC. Conta Gilberto Gil que:

Para abrigar os 50 mil negros do mundo inteiro que pra lá acorreram, tinha sido construída uma espécie de vila olímpica com pequenas casas feitas com material barato e um precário abastecimento de água e luz, que reavivou em mim a imagem física do grande conjunto habitacional pobre. Refavela foi estimulada por este encontro. ${ }^{56}$

A construção da letra é uma viagem entre a experiência de deslocamento para o continente africano e das possíveis relações com o contexto urbano brasileiro, que mesmo

\footnotetext{
${ }^{56}$ RENNÓ, Carlos. Gilberto Gil: todas as letras. São Paulo, Cia das Letras, 2003.
} 
distinto, apresentava pontos em comum. A seguir, está disposta a letra:

A refavela
Revela aquela
Que desce o morro e vem transar
O ambiente
Efervescente
De uma cidade a cintilar
A refavela
Revela o salto
Que o preto pobre tenta dar
Quando se arranca
Do seu barraco
Prum bloco do BNH

A noção de "comunicação" e de "movimento" representa o momento da Música da Diáspora Africana no Brasil. Se o sistema de representações fosse satisfatório, ele não permitiria o surgimento do conflito, isto é, a condição de regularidade de expressões e termos cuja significação visa comunicar, mas, sobretudo desarticular um padrão homogeneizante violento para com a figura dos africanos na diáspora.

A experiência negra de si para o outro é relativa, na medida das forças racistas dos contextos. Isto é, a autorreflexão de si (experiência racializada) se afirma no reconhecimento da miséria da raça construída pelo outro. A consciência negra "é" no momento da desgraça da raça, no esquecimento da raça, sua anuência.

A letra "Mama África" de Chico César constrói uma conjuntura de elementos transnacionais de origem e de autorreflexão idealizada de contextos. De acordo com a letra:

Mama África tem tanto o que fazer

além de cuidar neném

além de fazer denguim

filhinho tem que entender

Mama África vai e vem

mas não se afasta de você.

Nessa letra, o autor brinca com a conexão das palavras colocadas estrategicamente com sentidos duais capazes de mostrar aquele que escuta a canção, o acesso a uma realidade racializada. A utilização de elementos nativos como "neném" e "denguim" promove a introjeção africana para a realidade da discriminação social no Brasil, enegrecendo-a. Essa racialização permite admitir muito mais do que uma mulher pobre na labuta diária, mas uma mulher cujo passado histórico não nasceu colado à imagem da escravidão, e, nesse contexto, sua pós-história não pode ser figurada na mais nova e "legítima" descendente de escravas. A figura da mulher 
negra é africana!

Mama África transita - vai e vem - não apenas de sua casa, seja "lá onde for", numa periferia marginalizada e empobrecida de uma metrópole para o trabalho. É também, a partir da estratégia de utilização de elementos do tronco linguístico bantu na letra, possível acessar a interpretação da presença africana que "está" sempre presente, mas, pela autorreflexão branca da miséria da raça, se torna ausente, e pior, violentamente colocada como herança maldita da escravidão.

Essa análise é permitida a partir da continuação da letra da canção de Chico César:

Quando mama sai de casa/ seus filhos se olodunzam/ rola o maior jazz mama tem calo nos pés/ mama precisa de paz/ mama não quer brincar mais filhinho dá um tempo/ é tanto contratempo no ritmo de vida de mama

As experiências negras pós-coloniais e os assentamentos construídos referem-se à estamentos com reflexidade histórica maior que acreditamos existir. As produções culturais não apenas contém o sentimento da história nas suas interfaces dialéticas, mas são, correspondências históricas para além dos relatos históricos exitosos da nossa historiografia ocidental.

O momento da Música da Diáspora Africana no Brasil é o reposicionamento da cultura negra em reação aos padrões nacionalistas pré-estabelecidos. A necessidade de posicionamento linguístico por meio de um léxico gramatical africanizado introduz, no discurso poético das letras, expressões africanas e afro-brasileiras. Esta estrutura comunicativa permite notar uma ruptura com o legado híbrido, cuja expressividade orientou, não apenas o destino da música popular no Brasil como também o padrão de valores e de estética nacionais. Aliado a essa estrutura comunicativa, formas desterritorializadas foram interpostas nas produções culturais no campo da música negra. O "movimento" do cotidiano nacional-transnacional só pôde ser evidenciado no momento que foi interpretado, não como fenômeno nacional, mas como movimento diaspórico. Isso abriu um novo olhar intelectual para as proposições criativas da política cultural negra como estruturas de sentimento que criaram culturas afro-atlânticas e romperam as amarras do pertencimento nacional.

São expressões musicais consideradas revolucionárias. Se os agentes da música da Diáspora Africana são capazes de produzir lágrimas nas multidões em suas apresentações, que tipo de produto podem realizar todos juntos? Eles não são apenas cantores e cantoras organizando suas vidas, muitas desajustadas pelo racismo. Propomos que sejam muito mais do que isso! 


\section{Referência Bibliográfica}

BERND, Zila. O elogio da crioulidade: o conceito de hibridação a partir dos autores francófonos do Caribe. In: JUNIOR, Benjamin Abdala (org.) São Paulo: Boitempo, 2004.

BLACK, Marc. "Fanon and DuBoisian Double Consciousness," Human Architecture: Journal of the Sociology of Self-Knowledge: Vol.5: Iss. 3, Article 36. 2007.

BRUBAKER, Roger. The Diaspora "diáspora". Ethnic and Racial Studies, Vol. 28 no 1 - January, 2005 pp. 1-19.

BUCHER, KARL. Arbeit und rythmus, Leipizig, 1896

BUCK-MORSS, Susan. Hegel e o Haíti, NOVOS ESTUDOS CEBRAP 90, julho 2011 pp. 131-171 The origin of negative dialectics - Theodore Adorno, Walter Benjamin, and the

Frankfurt Institut, New York, The Free Press, 1977.

BLUTER, Kim. D. Defining Diaspora, Refining a Discourse. Diaspora. 10:2, 2001.

CESAR, Chico. Cantáteis: Cantos elegíacos de amozade, Rio de Janeiro, Garamond, 2005.

DU BOIS. W.E.B. The Souls of Black Folks. Chicago, 1903

CHERNOFF, John M. African Rhythm and African Sensibility: Aesthetics and Social Action in African Musical Idioms. Chicago: University of Chicago Press,1979.

DAVIS, Angela Y. If They Come in the Morning: Voices of Resistance. New York: Third Press, 1971a. FANON, Frantz. Os condenados da terra. Rio de Janeiro: Civilização Brasileira, 1979.

FANON, Frantz. Pele negra máscaras brancas (1951). Título original: "Peau noire, masques blancs". Salvador: EDUFBA, 2008.

FERNANDES, Florestan. A Integração do Negro na Sociedade de Classes. V. I e II. São Paulo: Editora Dominus, 1965.

GILROY, Paul. O Atlântico Negro - Modernidade e Dupla Consciência. Rio de Janeiro, Editora 34/UCAM, 2001.

GLISSANT, Édouard. Introdução a uma poética da Diversidade. Trad. Enilce Albergaria Rocha. Juiz de Fora: UFJF, 2005

GORDON, Lewis R. Existential Dynamics of Theorizing Black Invisibility. In: GORDON, Lewis R. (ed.). Existence in Black: An Anthology of Black Existential Philosophy. New York: Routledge, 1997. . Fanon, Philosophy, and Racism. In: BABBITT, Susan E. e CAMPBELL, Sue (ed.). Racism and Philosophy. Ithaca, New York: Cornell University Press, 1999.

.Fanon's critique of failed dialectics of recognition. In: An Introduction to Africana Philosophy. Cambridge Introductions to Philosophy, 2008.

Prefácio. In: FANON, Frantz. Pele negra máscaras brancas (1951). Título original: "Peau noire, masques blancs". Salvador: EDUFBA, 2008.

HARRISON, Faye V. "Introduction: Expanding the Discourse on 'Race.'” American Anthropologist 100(3):609-31. 1998

HALL, S. Da Diáspora. Identidades e Mediações Culturais. (org.) SOVIK, Liv. Belo Horizonte: Editora UFMG, 2009.

Identidade cultural na pós-modernidade.(trad.)SILVA, Tomaz Tadeu

HANCHARD, Michael George. Orfeu e o Poder: Movimento Negro no Rio e São Paulo (1945-1988). Rio de Janeiro: EDUERJ, 2001. 
HOOKS,Bell e WEST, Cornel Breaking Bread, Boston: South End Press, 1991.

ITZIGSOHN, José; BROWN, Karida. Sociology and the theory of double consciousness, 2015

KEIL, Charles. "The Theory of Participatory Descrepancies: A Progress Report." Ethnomusicology 39(1):1-19. 1995

KOTHE, F. R. Benjamin e Adorno: confrontos. São Paulo, Ed. Ática, 1978.

MANNING, Patrick. Africa And The African Diaspora: New Directions Of Study. Journal of African History, 44, 2003, pp. 487-506.

MONSON, Ingrid. The African Diaspora: A Musical Perspective. Routledge New York/London, 2003. PINHO, Patricia Santana, Mama Africa: Reinventing Blackness in Bahia. Translated by Elena Langdon. Durham, N C and London: Duke University Press, 2010

RABAKA, Reiland. Reconstructing the Black Radical Tradition, from W. E. B. Du Bois and C. L. R. James to Frantz Fanon and Amilcar Cabral. Lexingtonbooks, 2009.

RAWLS , Anne Warfield. "Race" as an Interaction Order Phenomenon: W. E. B. Du Bois's "Double Consciousness" Thesis Revisited. Sociological Theory, 18 ( 2 ): $241-274-2000$.

RENNÓ, Carlos. Gilberto Gil: todas as letras. São Paulo, Cia das Letras, 2003

RESTREPO, Eduardo "Afro-colombianos, antropología y proyecto de modernidad en Colombia". In María Victoria Uribe e Eduardo Restrepo (orgs.), Antropología en la modernidad: identidades, etnicidades y movimientos sociales en Colombia. Bogotá, Instituto Colombiano de Antropología. 1997

SAID, Edward W. Orientalismo. O oriente como invenção do ocidente. São Paulo: Companhia das Letras, 2007.

SAFRAN, William. "Diasporas in Modern Societies: Myths of Homeland and Return." Diaspora, 1991, 1(1)p: 83- 99.

SANTOS, Eufrázia Cristina Menezes. Resenha: Gilroy, Paul. O Atlântico Negro. Modernidade e dupla consciência, São Paulo, Rio de Janeiro - REVISTA DE ANTROPOLOGIA, SÃO PAULO, USP, 2002, V. 45 № 1.

SILVÉRIO, Valter R. O Programa Brasil-África na Construção da Ideia de Diáspora Africana. Revista do PPGCS - UFRB - Novos Olhares Sociais | Vol.1 - n.1 - 2018.

SPIVAK, GAYATRI, A critique of postcolonial reason, Cambridge, London, Harvard University Press, 1999

WADE, Peter. Blackness and race mixture: the dynamics of racial identity in Colombia. Baltimore, Johns Hopkins University Press,1993.

"The cultural politics of blackness in Colombia". American Ethnologist, vol. 22, no 2, pp. 342-358. 1995

"Blackness, music and national identity: three moments in Colombian history".

Popular Music, vol. 17, no 1, pp. 1-19. 1998

"Working culture: making cultural identities in Cali, Colombia". 1999

Press. 2000.

"Music, race and nation: Música Tropical in Colombia. Chicago, University of Chicago

WEST, Cornel, Questão de raça. CIA das Letras, São Paulo, 1994.

.The New Cultural Politics of Difference, Outubro, 53,1990, 93-109. 
Dener Santos Silveira: Doutorando do Programa de Pós-graduação em Sociologia da Universidade Federal de São Carlos PPGS/UFSCAR, mestre em Sociologia PPGS/UFSCAR(2011). Foi colaborador do Curso de História e Cultura Afro-brasileira, financiado pela United Negro College Funds e USAID em colaboração com o African World Institut da Fort Valley State University/USA, Integrante da Equipe de Avaliação do Programa Pathways to Higher Education Initiative da Fundação Ford dirigido ao ingresso e Permanência de Negros no Ensino Superior no Brasil. É membro do Núcleo de Estudos Afro-Brasileiros da Universidade Federal de São Carlos/NEAB/UFSCAR. Foi membro do Fórum Intergovernamental de Políticas de Promoção da Igualdade Racial/FIPIR da Secretaria Especial de Políticas de Promoção da Igualdade Racial/SEPPIR da Presidência da República.

José Ricardo Marques dos Santos: Doutorando do Programa de Pós-graduação em Sociologia da Universidade Federal de São Carlos PPGS/UFSCAR. Graduado em ciências sociais pela universidade federal de São Carlos (UFSCar) e mestre pela mesma instituição. Foi professor de sociologia e antropologia das Faculdades Frutal (MG) de 2007 a 2010, professor da Faculdades Barretos (SP) em 2007 e entre 2012 e 2014, fui chefe de divisão de Políticas de Promoção da Igualdade Racial da cidade de São Carlos, de 2010 a 2012.

Artigo recebido para publicação em: Outubro de 2018.

Artigo aprovado para publicação em: Novembro de 2018. 